\title{
FORMAÇÃO DOCENTE: REFLEXÕES DE ALUNOS DE PEDAGOGIA NO PROGRAMA BOLSA ALFABETIZAÇÃO'
}

ANA SÍLVIA MOÇO APARÍCIO

\section{RESUMO}

Este artigo tem como objetivo apresentar e discutir os principais resultados de uma pesquisa que buscou compreender o processo de formação docente de alunos de Pedagogia participantes do Programa Bolsa Alfabetização. Para tal, buscou-se analisar como esses alunos reconfiguram o agir do professor-regente nos/pelos relatos reflexivos que eles produzem no âmbito do programa. Os pressupostos teórico-metodológicos que orientam as análises são do interacionismo sociodiscursivo. Os resultados apontam a necessidade de ampliação da formação do alfabetizador para os estudos de didática das línguas, que aborda a análise das práticas de sala de aula privilegiando as formas de adequação do ensino às capacidades dos alunos, às interações, às tarefas realizadas, aos objetos efetivamente ensinados na aula, e às ferramentas/instrumentos de ensino.

1 Este trabalho é resultado de uma pesquisa de estágio pós-doutoral realizado na Fundação Carlos Chagas. 


\section{RESUMEN}

Este artículo tiene como objeto presentar y discutir los principales resultados de una pesquisa que trató comprender el proceso de formación docente de alumnos de Pedagogía participantes del Programa Bolsa Alfabetização. Para eso, se trató analizar como eses alumnos (re)constituyen el actuar del profesor-regente en los/por los relatos reflexivos que ellos producen en el ámbito del Programa. Los presupuestos teórico-metodológicos que orientan el análisis son de la Interacción Socio-discursiva. Los resultados del análisis demuestran la necesidad de ampliación de la formación del alfabetizador hacia los estudios de la didáctica de las lenguas, que aborda la análisis de las prácticas del Aula de Clase, privilegiando las formas de adecuación de la enseñanza a las capacidades de los alumnos, a las interacciones, a las tareas realizadas, a los objetos efectivamente enseñados en la clase, a las herramientas/instrumentos de enseñanza.

PALABRAS-CLAVE FORMACIÓN DE PROFESORES •

ALFABETIZACIÓN・PRÁCTICA EDUCATIVA.

\section{ABSTRACT}

This article aims to present and discuss the main results of a survey that sought to understand the teacher training process of Pedagogy students who participate in the Bolsa Alfabetização Program. In order to achieve this goal, we analyzed how these students reconfigure the teacher's acting by means of the reflexive reports they produce under the Program. The theoretical-methodological assumptions that guide the analyses are based on Socio-Discursive Interactionism. The results indicate the need to expand the literacy teacher's training toward studies of language teaching which deal with the analysis of classroom practices that emphasize ways of making teaching appropriate to students' abilities, interactions, tasks performed, objects effectively taught in the classroom, and also to the teaching tools.

KEYWORDS TEACHER EDUCATION • LITERACY •

EDUCATIONAL PRACTICE. 
2 Firmada a parceria, a SEE repassa às IESs os recursos necessários ao atendimento das despesas com a concessão de bolsas-auxílio aos alunos participantes do programa.

3 Neste trabalho chamaremos de alunos-bolsistas, para evitar confusões terminológicas.

\section{INTRODUÇÃO}

Neste artigo, apresentamos e discutimos os principais resultados de uma pesquisa em que buscamos compreender mais detalhadamente o processo de formação docente de alunos de Pedagogia, da Universidade Municipal de São Caetano do Sul (USCS), participantes do Programa Bolsa Alfabetização implantado pelo governo do Estado de São Paulo.

Em linhas gerais, o Bolsa Alfabetização é um programa que, por uma parceria entre a Secretaria da Educação do Estado de São Paulo (SEE-SP) e a Fundação para o Desenvolvimento da Educação (FDE) e Instituições de Ensino Superior ${ }^{2}$ (IES), oferece oportunidades a universitários, que frequentam cursos de Pedagogia ou Letras, de vivenciar, com professores da rede pública estadual, em sistema de colaboração, a prática de uma escola real, objetivando a ampliar o significado da teoria estudada no âmbito acadêmico.

Desse modo, a tarefa dos universitários participantes do programa, denominados "alunos-pesquisadores", ${ }^{3}$ é auxiliar os professores-regentes de $2^{\circ}$ ano (antiga $1^{\mathrm{a}}$ série) a realizarem a alfabetização e, além disso, transformar a experiência em 
temário de análise e discussão na IES, onde são acompanhados e orientados por um professor orientador, com vistas a desempenharem com sucesso o trabalho de alfabetização e desenvolverem trabalhos de pesquisa sobre temas relacionados à alfabetização. A esse professor orientador, indicado pela IES, cabe realizar encontros semanais com os alunos-bolsistas $(\mathrm{AB})$, visando orientar, discutir e refletir sobre o trabalho desses nas escolas. Uma das propostas da Equipe da SEE/FDE aos professores orientadores, para o acompanhamento desse trabalho, é que motivem e orientem os ABs a registrarem diariamente as observações e intervenções realizadas na sala de aula em que atuam, considerando-se que a produção e análise dos registros escritos é um importante recurso de formação profissional e de desenvolvimento pessoal.

Nesse contexto, o envolvimento demonstrado pelos ABs da Universidade Municipal de São Caetano do Sul, com relação às experiências vivenciadas nas salas de aula em que atuam, chamaram-nos a atenção e nos levaram a refletir sobre a possibilidade de construção de um diálogo diferente, provocado pelo Bolsa Alfabetização, entre a instituição de formação docente e a instituição escolar. Diferente, sobretudo, em comparação à assimetria do diálogo entre essas mesmas instâncias, tradicionalmente instaurado pelo Estágio Supervisionado dos cursos de formação de professores.

Ao tomar a escola como palco central da formação inicial, da formação continuada e da prática de sala de aula, o Bolsa Alfabetização tende a instaurar um espaço real em que as questões da educação possam ser discutidas colaborativamente pela universidade e pela escola, permitindo a construção de novas formas de interação no processo de formação docente, inclusive com a participação de novos papéis e atores nesse processo, tais como: o professor-regente, o aluno-bolsista, o professor orientador.

Foram, então, essas reflexões que nos instigaram a realizar uma pesquisa que teve como foco o processo de formação dos ABs e, como objeto de análise, os relatos reflexivos desses alunos, oriundos de suas observações, indagações, intervenções, realizadas na sala de aula de alfabetização em que atuam com o professor-regente. 
4 Neste estudo, utilizo os termos "(re)configurar" e "(re)configuração",

com base em Bronckart (2008,

p. 35,), no sentido de que dizer o mundo é uma constante atividade de configuração e refiguração. Assim, para Bronckart, "qualquer texto, qualquer que seja seu gênero ou seu tipo, seja oral ou escrito pode contribuir no processo de reconfiguração do agir humano".
Estamos considerando "relato reflexivo" como um gênero textual de cunho autobiográfico que, de acordo com Signorini (2006), incorpora as duas funções principais que têm sido atribuídas a relatos de experiência pessoais escritos por professores em contextos de interlocução orientada para atuação no ensino - interlocução essa realizada com os seus pares e/ou com o professor formador. Nos termos da autora,

A primeira dessas funções é a de dar voz ao professor enquanto profissional. Através do "relato reflexivo", são desencadeados processos de articulação e legitimação de posições, papéis e identidades autorreferenciadas, ou seja, construídas pelo narrador/autor para si mesmo. A segunda função é a de, através da interlocução mediada pela escrita, criar mecanismos e espaços de reflexão sobre teorias e práticas que constituem os modos individuais e coletivos de compreensão e de produção/reprodução desse campo de trabalho, bem como das identidades profissionais, individuais e de grupo. (SIGNORINI, 2006, p. 55)

Nesse sentido, consideramos que os relatos reflexivos produzidos por ABs do Programa Bolsa Alfabetização constituem um importante objeto para estudo, uma vez que, ao possibilitar a esses alunos refletir na/pela escrita sobre as práticas docentes observadas, as suas próprias ações e práticas, trazem indícios de como estão compreendendo essas práticas e constituindo-se professores. Assim, na análise que realizamos, buscamos evidenciar e compreender como os ABs "(re)configuram" ${ }^{4}$ o agir do professor-regente nos/ pelos relatos reflexivos que produzem no âmbito do Bolsa Alfabetização. Com isso, como veremos mais adiante, foi possível desenvolver algumas reflexões sobre a formação docente dos licenciandos em Pedagogia participantes desse programa, como também sobre a formação de professores em geral.

Neste artigo, apresentamos, primeiramente, os pressupostos e características gerais do programa, com um breve histórico de sua operacionalização na USCS. A seguir, explicitamos os aportes teórico-metodológicos que fundamentaram 
nossa pesquisa, apontando as categorias de análise dos dados. No final, apresentamos os resultados das análises e as conclusões do estudo.

PROGRAMA BOLSA ALFABETIZAÇÃO:

\section{PRESSUPOSTOS E CARACTERÍSTICAS GERAIS}

O Projeto Escola Pública e Universidade na Alfabetização conhecido como Programa Bolsa Alfabetização - foi inicialmente implantado pela Secretaria Municipal de Educação de São Paulo, em 2006. Em 2007 foi incorporado pela SEE-SP integrando o Programa Ler e Escrever, cujo objetivo é alfabetizar todas as crianças com até oito anos de idade das escolas estaduais, ou seja, até o final do $3^{\circ}$ ano do Ensino Fundamental, bem como garantir recuperação da aprendizagem de leitura e escrita aos alunos das demais séries que compõem os anos iniciais do Ensino Fundamental ( $4^{\circ}$ e $5^{\circ}$ anos).

O Ler e Escrever engloba um conjunto de linhas de ação articuladas que inclui formação, acompanhamento, elaboração e distribuição de materiais pedagógicos e outros subsídios, constituindo, dessa forma, uma política pública para as séries iniciais do Ensino Fundamental que busca promover a melhoria do ensino em toda a rede estadual.

Considerando que a formação inicial dos professores não tem contemplado adequadamente a didática da alfabetização e, também, não, outros conhecimentos sobre a prática (GATTI et al. 2008; GATTI; NUNES, 2009), e se somando ao fato de que o grande número de alunos por sala de aula (geralmente em torno de 40) dificulta o trabalho individualizado do professor-regente, sobretudo, com as crianças que apresentam maiores dificuldades no processo de alfabetização, é que a SEE-SP, em parceria com a FDE, estruturou o Programa Bolsa Alfabetização. Assim, o propósito principal desse programa é o de trazer à tona, em parceria com as IES envolvidas, questões que envolvem a didática da alfabetização, tendo como referência a prática educativa real da sala de aula, na busca de constituição/construção de conteúdos mais adequados para a formação inicial de professores. 
Assim, o Bolsa Alfabetização intenciona aprimorar a formação inicial dos estudantes dos cursos de Pedagogia e de Letras, possibilitando-lhes atuar, diariamente, com os professores alfabetizadores da rede pública de ensino, tendo maior conhecimento dessa realidade e, consequentemente, contribuir para que todos os alunos do $2^{\circ}$ ano ou de classes do mesmo ciclo, voltadas à recuperação da aprendizagem como as classes de Projeto Intensivo no Ciclo (PIC),) sejam capazes de ler e escrever convencionalmente. Além disso, espera-se que as IES comprometam-se com a causa do ensino público, buscando estabelecer uma ponte importante entre o ambiente acadêmico e a prática em sala de aula, por uma interação permanente do $\mathrm{AB}$ com o professor-regente e com o professor orientador da IES. Como ressalta Telma Weisz, o Programa Ler e Escrever,

[...] diferentemente dos anteriores, foi oficialmente assumido como política pública desde o seu início. Isto é, não era mais um grupo de educadores que se dispunha a, voluntariamente, fazer a diferença. Houve, por exemplo, a necessidade de mudar normas e legislação para garantir as condições de funcionamento minimamente necessárias. Só uma política pública poderia produzir material didático impresso (a tradição no Brasil é o Estado comprar material didático das editoras privadas para distribuir gratuitamente) para professores e alunos, tanto os das escolas estaduais como os das escolas municipais que se integraram ao Programa. E, como cabe a uma política pública, o Ler e Escrever não está focado na formação em serviço dos professores individualmente, mas foi pensado como um conjunto de ações cujo objetivo é fazer avançar a qualidade do ensino oferecido em cada escola. (2010, p. 21)

Com relação ao embasamento teórico, no entanto, o Programa Ler e Escrever e o Bolsa Alfabetização mantêm a orientação construtivista de alfabetização, assumida há pelo menos 25 anos pelo Estado de São Paulo, embasada nas contribuições teóricas e metodológicas, inicialmente publicadas em Psicogênese da língua escrita (FERREIRO; TEBEROSKY, 1985), amplamente divulgadas e recomendadas aos professores. 
Nessa obra, amparadas nas ideias de Piaget sobre a construção do conhecimento, as autoras demonstram como a criança constrói diferentes hipóteses acerca da escrita, antes de chegar a compreender a base do sistema alfabético.

Com essa premissa, o Programa Bolsa Alfabetização alinha as concepções de língua, de alfabetização e letramento, de ensino e aprendizagem da leitura e escrita, assumindo a ideia de que alfabetizar significa muito mais do que ensinar a codificar e decodificar textos simples e, por isso, estar alfabetizado significa saber usar, de modo autônomo, os recursos da sua própria língua nas diferentes situações.

Considerando que as crianças refletem sobre a escrita e desenvolvem complexas hipóteses para explicar as regularidades do sistema, as orientações do programa salientam que os conhecimentos construídos pelas crianças não surgem espontaneamente, é preciso que lhes sejam dadas, nas diversas situações de leitura e escrita, oportunidades de refletirem sobre o sistema de escrita. Dessa forma, a escola e, sobretudo, o professor são responsáveis por inserir os alunos no universo da cultura escrita, ressaltando ser necessário, para o sucesso na alfabetização, ter uma rotina de leitura e de escrita na escola, assim como, realizar projetos e sequências didáticas que levem os alunos a refletir não apenas sobre o funcionamento do sistema de escrita, mas sobre os usos e funções da língua.

No que se refere ao processo de formação docente, a grande inovação do programa, está, a nosso ver, na adoção da investigação didática que busca instigar os ABs a observarem mais atentamente as situações de ensino e aprendizagem que vivenciam e a refletirem sobre como as práticas pedagógicas de alfabetização podem ser mediadas por conhecimentos sobre a didática da língua, em funcionamento em contextos reais de sala de aula.

De acordo com Lerner (2002), a pesquisa didática elege as práticas de sala de aula como objeto de análise, considerando as situações de classe, as diferentes formas de registros sobre essas situações e as discussões feitas sobre esses registros com os professores envolvidos, transformando tudo em ferramentas essenciais para se construir e divulgar conhecimentos próprios da área e para ela. 
Essa perspectiva de adotar como objeto de análise a própria prática do professor é defendida por Lerner (2002) com base na ideia de que, para a inovação/mudança de práticas em sala de aula, não basta somente a capacitação dos professores. Nos termos da autora:

Reconhecer que a capacitação não é condição suficiente para a mudança na proposta didática porque ela não depende só das vontades individuais dos professores - por melhor capacitados que estejam - significa aceitar que, além de continuar com os esforços de capacitação, será necessário estudar os mecanismos ou fenômenos que ocorrem na escola e impedem que todas as crianças se apropriem dessas práticas sociais que são a leitura e a escrita [...] Ao conhecê-los, se tornará possível vislumbrar formas de controlar sua ação, assim como precisar algumas questões relativas à mudança curricular e institucional. (LERNER, 2002, p. 33)

É, pois, nesse sentido, que a autora aponta a necessidade de investigações didáticas específicas, como na área da leitura e da escrita, para que se produzam conhecimentos resolvendo problemas específicos da área, de tal modo que a didática da leitura e da escrita deixe de ser matéria "opinável" para constituir um corpo de conhecimentos de reconhecida validade. Pois, de acordo com Lerner (2002), o conhecimento didático de língua materna, por exemplo, não pode ser deduzido simplesmente das contribuições da psicologia ou da linguística. "É necessário realizar investigações didáticas que permitam estudar e validar as situações de aprendizagem que propomos, aperfeiçoar as intervenções de ensino, apresentar problemas novos que só se fazem presentes na sala de aula" (LERNER, 2002).

Assumindo essa abordagem para nortear o processo de formação dos ABs, o Programa Bolsa Alfabetização busca envolvê-los com os problemas próprios das ações didáticas na alfabetização. Para isso, a orientação é que os ABs participem do cotidiano do processo de alfabetização de crianças, observando e atuando com os alunos, e a devida orientação do professor-regente e supervisão do professor orientador, produzindo registros escritos e/ou audiogravados das situações 
observadas/vivenciadas nesse contexto. Registros esses que devem servir para orientar o olhar investigativo do $\mathrm{AB}$, bem como o foco da investigação didática a ser realizada, mediante a seleção de um, dentre os quatro temas propostos: Rotina de leitura e de escrita; Leitura feita pelo professor; Produção oral com destino escrito; Cópia e ditado (ressignificação da cópia).

Os conteúdos e metodologias relativos a esses temas devem ser sistematicamente trabalhados e estudados nos encontros de formação da IES, ao longo do ano, conforme o Plano de Trabalho aprovado pela FDE.

\section{O PROGRAMA BOLSA ALFABETIZAÇÃO NA USCS}

Na USCS, o Bolsa Alfabetização teve início em agosto de 2008, quando foi firmado o primeiro convênio desta IES com a SEE/ FDE $^{5}$, mediante aprovação do Plano de Trabalho elaborado pelo Curso de Pedagogia. Nesse ano, o programa contou com a participação de aproximadamente 30 ABs. De 2009 até o primeiro semestre de 2012, o número de participantes do programa tem-se mantido em aproximadamente $50 \mathrm{ABs}$ por ano. Desde o início do programa na USCS, os ABs atuam em classes de $2^{\circ}$ ano ou em classes de PIC, de escolas das Diretorias de Ensino de Santo André, Mauá e Diadema, e das Diretorias de São Paulo que se avizinham a São Caetano do Sul: Leste 4, Leste 5 e Centro Sul. Nesse período de quatro anos, aproximadamente 200 alunos da pedagogia da USCS já participaram, pelo menos durante um semestre, do Bolsa Alfabetização.

Para a formação, orientação e acompanhamento desses alunos, a USCS designou em 2008, permanecendo até hoje, duas professoras do Curso de Pedagogia, sendo eu uma delas, ${ }^{6}$ por lecionar as disciplinas fundamentos e metodologia da alfabetização e metodologia e prática do ensino de língua portuguesa no referido curso; disciplinas que evidentemente tratam, entre outros aspectos, dos processos de ensino e aprendizagem da leitura e da escrita durante o período de alfabetização.

Um procedimento que adotamos, nesse processo de formação - que merece ser mais detalhado aqui em razão de
5 O contrato tem a duração de um ano, por isso, a cada ano, a IES tem de apresentar um novo Plano de Trabalho para ser avaliado, com a devida documentação. Sendo aprovado, firma-se novo contrato.

6 A outra professora designada para a função de professor orientador é responsável pelas disciplinas didática e prática de ensino, didática para Educação Infantil e didática para - Ensino Fundamental, tendo em vista que essas disciplinas abordam questões relacionadas ao ensino e à aprendizagem na alfabetização. 
melhor esclarecer o contexto de produção do nosso objeto de pesquisa - é a orientação ao $\mathrm{AB}$ para a produção sistemática dos relatos reflexivos, em que expresse suas observações, impressões, experiências, indagações, conflitos, autorreflexões sobre o que observa e o que vivencia na classe de alfabetização em que atua. Trata-se, portanto, de um texto de caráter mais subjetivo, em que se descreve não só os movimentos do mundo exterior como também do mundo interior, da consciência. Nesse tipo de escrita, o autor do texto deixa transparecer o seu pensamento na procura de explicações para suas observações, constituindo, assim, um lugar de reflexões sistemáticas, constantes, ou seja, um espaço em que o autor conversa consigo mesmo, anota questionamentos, opina sobre o processo de aprendizagem das crianças, sobre as intervenções do professor e possíveis encaminhamentos.

É importante lembrar também que para a produção inicial dos relatos reflexivos foram lidos e discutidos diferentes textos desse gênero, abordando temáticas variadas (relatos de licenciandos em formação, de professores-regentes, de professores em formação continuada, entre outros) e, assim, os ABs foram sendo estimulados a produzirem os próprios textos.

É, portanto, considerando essas possibilidades, que elegemos os relatos reflexivos como objeto de discussão e análise na formação do $\mathrm{AB}$ na USCS, pois, acreditamos que, assim, possibilita-se construir uma relação mais consciente da prática com a teoria, uma vez que permite que o futuro professor tenha nas mãos o processo de fazer e o de aprender com o fazer. Como afirma Telma Weisz:

$O$ ato de refletir por escrito possibilita a criação de um espaço para que a reflexão sobre a prática ultrapasse a simples constatação. Escrever sobre alguma coisa faz com que se construa uma experiência de reflexão organizada, produzindo, para nós mesmos, um conhecimento mais aprofundado sobre a prática, sobre as nossas crenças, sobre o que sabemos e o que não sabemos. (2002, p. 129)

Cabe lembrar que os relatos reflexivos produzidos ao final de cada mês pelos ABs são entregues às professoras orientadoras, para a realização de devolutivas aos ABs e 
também para que possamos (re)pensar nossas ações de formação e (re)orientar a atuação desses alunos. Os relatos reflexivos também nos ajudam nas reflexões que apresentamos nos relatórios pedagógicos trimestrais entregues à equipe da SEE/FDE gestora do programa.

Certamente, essas produções escritas dos ABs ainda permitem muitas análises e interpretações. Uma das possibilidades é a que procuramos realizar em nossa pesquisa, quando analisamos os relatos reflexivos produzidos pelos ABs da USCS, com o objetivo de compreender como, na/pela escrita, eles (re)configuram modos de agir do professor-regente e, assim, vão se constituindo professores.

\section{APORTES TEÓRICO-METODOLÓGICOS DA PESQUISA}

A reflexão na/sobre a prática passou a ser palavra de ordem não apenas nas ações de programas de formação inicial e continuada de professores, mas também como tema de muitos estudos e pesquisas da área de formação docente. $\mathrm{Na}$ perspectiva de estudos que relacionam linguagem e trabalho educacional, realizados sobretudo no campo aplicado dos estudos da linguagem, essa reflexão é enriquecida pelas abordagens de análise das práticas de linguagem que emergem nos contextos de ensino, abordagens essas que têm em comum uma concepção de linguagem como atividade social, em que a interação é objeto básico e privilegiado para se chegar a conhecer a prática social (BAKHTIN, 1981).

Dessa forma, o objeto de análise não é apenas o conteúdo temático, mas também a própria linguagem, ou seja, as práticas de linguagem construídas em diferentes situações de ensino/aprendizagem, tais como as salientadas por Kleiman:

[...] alunos e alunos-professores em formação nas suas interações com docentes universitários; professores em atuação na sala de aula, pondo em evidência seus processos de formação; professores refletindo sobre suas práticas; professores interagindo com seus colegas no cotidiano escolar [...]. (2001, p. 21) 
Tendo isso em vista, para a análise dos relatos reflexivos, adotamos como referenciais teórico-metodológicos as contribuições do interacionismo sociodiscursivo (BRONCKART, 1999, 2004, 2006, 2008; MACHADO, 2004, 2008, 2009, entre outros), que assumem o papel fundador da linguagem e do funcionamento da atividade discursiva no desenvolvimento humano, enfatizando a dimensão interacional da linguagem e permitindo analisar o conteúdo e as condições de produção dos enunciados: o que é dito e os modos de dizer.

Tais referenciais, além de dar suporte para a compreensão dos diferentes aspectos que compõem a profissão docente, fornecem uma visão clara da importância da linguagem verbal no desenvolvimento e na interação humana, bem como um modelo de análise de texto que possibilita compreender a relação entre os textos e o agir docente no processo do desenvolvimento humano e profissional.

O trabalho do professor em sala de aula é uma realidade social complexa, no sentido definido por Morin (1996), de um todo que comporta um emaranhado de ações, de interações e de retroações. Na tentativa, então, de apreender, nos relatos reflexivos dos ABs, aspectos da formação desses alunos, quando expostos ao trabalho de um professor (o professor-regente), consideramos necessário assumir uma concepção do trabalho de ensino que busca compreender a complexidade dessa tarefa, levando em conta as diversas dimensões que fazem parte do trabalho do professor, aliadas a uma abordagem discursiva.

Para isso, adotamos também referenciais de abordagens que compreendem o ensino como trabalho, desenvolvidas no campo das ciências do trabalho, principalmente em países francófonos e, mais recentemente, incorporadas por grupos de pesquisa no Brasil, que atuam no campo dos estudos da linguagem e/ou no campo da educação (MACHADO, 2004). São abordagens que concebem o trabalho como um tipo de agir humano, tendo o coletivo de trabalho sempre presente, mesmo in absentia, uma vez que há uma memória profissional onipresente; além disso, o trabalho é situado em um dado contexto, estruturado por regras, convenções, culturas, havendo uma interação 
entre o trabalhador e o ambiente físico e social, mediado por instrumentos materiais ou simbólicos/discursivos. $\mathrm{O}$ trabalhador age, assim, direta ou indiretamente, utilizando artefatos/instrumentos, sobre o meio da atividade de trabalho, transformando-os e sendo transformado por ele (MUNIZ-OLIVEIRA, 2011).

Tendo em vista que nosso interesse era analisar textos descritivos/interpretativos/reflexivos (os relatos reflexivos) produzidos por observadores e participantes (os ABs) da atividade educacional, abordamos especificamente questões, na perspectiva do interacionismo sociodiscursivo (ISD), referentes ao agir humano e ao conjunto de procedimentos semânticos de análise de texto, buscando detectar as formas de agir construídas em um texto.

Para o estudo do agir, Bronckart e seus seguidores consideram dois níveis de análise: o contexto imediato e sócio-histórico da produção do texto; e o textual/discursivo. No nível de análise do contexto de produção, são levados em conta parâmetros físicos (o lugar físico do contexto de produção; quem é o emissor, o receptor; qual é o espaço-tempo da produção) e parâmetros sociossubjetivos, em que se levantam hipóteses para compreender o local social de onde fala/escreve o enunciador, para qual destinatário o texto foi provavelmente produzido, em qual local social ele foi produzido, quais os objetivos da interação e que efeitos o enunciador queria produzir no destinatário.

No nível de análise textual/discursiva, são consideradas três dimensões que compõem a arquitetura interna dos textos, denominada por Bronckart (1999) "folhado textual": a organizacional, composta pela infraestrutura geral do texto; a enunciativa, constituída pelos mecanismos de responsabilização enunciativa, isto é, as modalizações e as vozes presentes no texto; e a semântica, que permite identificar elementos semânticos ou categorias do agir (BRONCKART; MACHADO, 2004).

Como na análise que realizamos interessaram mais especificamente os procedimentos do nível organizacional e semântico, apresentamos aqui aspectos relacionados a esses dois níveis de análise, explicitando o sentido de alguns 
termos conceituais e categorias do agir utilizados nas análises dos relatos reflexivos, tomando por base estudos de Bronckart (2006); Bronckart e Machado (2004); Mazzillo (2006); Barricelli (2007); Bueno (2007) e Muniz-Oliveira (2011), que buscam identificar o agir (re)configurado nos textos.

No contexto do ISD, o termo "agir" designa genericamente qualquer forma de intervenção orientada no mundo, de um ou de vários seres humanos, os quais são nomeados como "actantes", ou seja, qualquer pessoa ou instituição implicada no agir. Por exemplo, podemos nos referir ao agir do professor-regente das classes de alfabetização, ao agir do $\mathrm{AB}$, ao agir do aluno, podendo, portanto, ser actantes o professor-regente, $\mathrm{o} A \mathrm{~B}$, os alunos, entre outros implicados no agir. Trabalhos dos autores citados têm evidenciado que, pela interpretação do agir, é possível dar-lhe significação, dizendo ao outro o que fazemos, como fazemos e, ainda, analisar o agir de outro ou o nosso próprio agir.

Tendo em vista nossos objetivos, analisamos os relatos reflexivos dos $\mathrm{ABs}$ com base em categorias identificadas por Mazzillo (2006) e Barricelli (2007) na interpretação do agir do professor em situações de ensino-aprendizagem e de formação docente. Os trabalhos dessas autoras evidenciam que o professor aparece quase sempre na posição de sujeito das orações, seguido por um predicado. Ou seja, nessa situação, podemos dizer que o agir do professor é representado na linguagem por predicados que têm o professor como sujeito. Analisando esses predicados, as autoras identificaram os seguintes modos de agir, os quais exemplificamos com trechos dos relatos reflexivos produzidos pelos ABs:

Agir linguageiro: identificado nos predicados que apresentam verbos de dizer ("explicar", "perguntar", "responder", “dizer" etc.). Essa figura do agir foi distribuída em três grupos de agir que:

a) implica uma ação imediata dos alunos. Por exemplo: "A professora pede que as crianças cantem junto com ela";

b) não implica uma resposta imediata. Por exemplo: "A professora explicou a atividades aos alunos"; 
c) está em relação ao agir dos alunos. Por exemplo: "Os alunos apresentaram dificuldades em realizar os problemas e a professora explicou mais uma vez".

Agir com instrumento/instrumental: identificado nos predicados que representam um agir verbalizado ou não do professor, com o uso de verbos que implicam a ideia de instrumento material como "pintar", "colar", "escrever", "xerocar", "imprimir”; ou simbólico como "ler”, "separar”, “cantar”. Por exemplo: "A professora lê e os alunos respondem na folha”. Agir mental/cognitivo: identificados nos predicados que indicam uma atividade mental ou capacidade das professoras. Por exemplo: "A professora criou um dia especial para as crianças levarem os livros para casa (mental); A professora tem domínio da organização da sala" (capacidade).

Agir prescritivo: envolve as prescrições para o agir do professor, marcado pelas relações predicativas indiretas deônticas, que envolvem valores como obrigação, dever (“dever", "ser preciso" etc.) e espistêmicas, que envolvem valores como verdade, probabilidade, certeza, crença ("poder", "ser verdade” etc.). Por exemplo: "O professor deve programar sua prática a partir do uso do material 'Ler e Escrever', assim ele poderá ter uma visão mais social”.

Agir afetivo: implica um agir emocional que é marcado por verbos como "gostar", "apreciar", "adorar", entre outros. Por exemplo: "O que mais me chama a atenção na professora é o carinho, a dedicação e o amor que ela sente pelos alunos."

Agir corporal: implica um agir físico, que é marcado por verbos como "abraçar", "andar”, "circular”, “caminhar”, “dirigir-se a” etc., relacionado, portanto, a gestos e movimentos corporais. Por exemplo: "A professora da sala tem me dado liberdade para atuar dentro desse espaço. Posso caminhar por toda a sala a qualquer momento".

Essas categorias permitem ao pesquisador evidenciar as (re)configurações que os observadores/participantes (alunos 
7 Cabe lembrar que, durante todo esse tempo no programa, nem sempre o $A B$ permaneceu na mesma escola ou com o mesmo professor-regente, pois, como o encaminhamento do $A B$ é realizado anualmente, sempre ocorrem mudanças. em formação; professores em formação) possuem das ações dos professores em situação de trabalho, que modos de agir do professor eles identificam em seus textos. Assim, utilizando essas categorias, buscamos identificar modos de agir do professor-regente (re)configurados pelo $\mathrm{AB}$ em seus relatos reflexivos.

Explicitamos os referenciais teórico-metodológicos e as categorias utilizadas na análise dos dados da pesquisa. A seguir trataremos dos procedimentos metodológicos e da análise propriamente dita dos relatos reflexivos.

\section{DESCRIÇÃO E ANÁLISE DOS DADOS DA PESQUISA}

Para a seleção dos relatos reflexivos que compõem o corpus da pesquisa, consideramos os que foram produzidos pelos alunos que participaram do Programa Bolsa Alfabetização na USCS desde o seu início (agosto 2008) até julho de 2011. A adoção desse critério de seleção deve-se ao fato de que, provavelmente, os ABs que permanecem no programa por mais tempo, possam explicitar melhor suas observações/interpretações do trabalho que vivenciam nas classes de alfabetização.

Seguindo esse critério, primeiramente, identificamos os alunos que permaneceram mais tempo no Programa 7 ABs. O passo seguinte foi separar os relatos produzidos por esses alunos entre agosto de 2008 e julho de 2011, obtendo 75 relatos ao todo.

Para a organização do corpus, e considerando que os relatos selecionados foram produzidos ao longo de três anos, entre o segundo semestre de 2008 e o primeiro semestre de 2011, optamos por trabalhar com os relatos reflexivos, organizados em três períodos: textos produzidos no primeiro ano do Programa (Período 1); no segundo ano (Período 2) e no terceiro ano (Período 3). Tendo em vista os objetivos da pesquisa, selecionamos, para a análise textual, 47 relatos produzidos pelos ABs no primeiro e no terceiro ano do programa.

Os 7 ABs produtores desses relatos são todos do sexo feminino, com idade entre 19 e 25 anos, provenientes da escola pública, pertencentes à classe média baixa e habitantes de regiões circunvizinhas da USCS. A maioria trabalhava 
como estagiárias, em escolas de Educação Infantil, no período inverso ao que atuavam no Bolsa Alfabetização, e no período noturno frequentavam o Curso de Pedagogia. Todas elas tinham um bom desempenho no curso e eram assíduas. De modo geral, são alunas que apresentam um domínio linguístico mediano, como poderá ser observado nos trechos dos relatos. Para a análise dos relatos reflexivos, utilizamos os seguintes procedimentos metodológicos:

1. Análise pré-textual: trata da situação de produção dos relatos reflexivos (o contexto físico e o contexto sociossubjetivo).

2. Análise textual: trata do

a) do plano global dos conteúdos temáticos dos relatos reflexivos;

b) do nível semântico (semiologia do agir), que diz respeito à identificação:

- dos actantes principais postos em cena nos/pelos textos relatos reflexivos (professor-regente, $A B$, alunos, pais etc.);

- dos modos do agir do professor-regente (re)configurados nos textos do $\mathrm{AB}$, ou seja, dos modos de agir que os $\mathrm{ABs}$ atribuem ao professor-regente;

- por meio dos adjetivos, substantivos, advérbios, avaliações/apreciações do $A B$ sobre um determinado modo de agir ou sobre elementos do trabalho docente na alfabetização.

\section{A SITUAÇÃO DE PRODUÇÃO DOS RELATOS REFLEXIVOS}

Ao assumir que os pré-construídos histórico-culturais exercem influência no agir humano e profissional, sendo cristalizados e sedimentados socialmente (BRONCKART, 2008), é preciso considerar que as representações sobre a situação de produção que os ABs mobilizam para a produção dos relatos reflexivos. Para isso, levantamos algumas hipóteses sobre essa situação de produção, em relação aos elementos do contexto que podem influenciar o texto, tanto sobre o contexto físico (lugar de produção/momento de produção), quanto sobre o contexto sociossubjetivo: instituição social, posição 
8 A partir do segundo semestre de 2010, quando iniciamos esta pesquisa os ABs tomaram conhecimento de que seus relatos seriam objeto da pesquisa. social dos interlocutores, relações de hierarquia ou poder institucional dos interlocutores, efeitos desejados sobre os destinatários etc.

Dessa forma, para compreender o contexto de produção dos relatos reflexivos, é preciso também levar em conta elementos que possam ser considerados como pré-construídos no decorrer da história que contribui para a constituição do trabalho do $\mathrm{AB}$. Já apresentamos alguns desses elementos na caracterização do programa de modo geral e de sua operacionalização na USCS. Focalizamos, agora, mais especificamente, algumas hipóteses sobre a situação imediata de produção de linguagem, no que diz respeito aos elementos do contexto sociossubjetivo que podem ter influenciado na produção dos seus relatos reflexivos.

Os relatos reflexivos são textos concebidos na esfera acadêmica, produzidos conforme os objetivos e orientações passados nos encontros de formação na USCS. O AB sabe que os seus relatos são lidos apenas pelas professoras orientadoras, e que servem de referência para as discussões nos encontros de formação e para os nossos relatórios enviados à FDE, ${ }^{8}$ mas sabem também que as professoras não vão revelar publicamente/nominalmente o que um determinado $A B$ relata. Com isso, é possível que os $\mathrm{ABs}$ tenham assumido, nos relatos, uma forma de escrita bastante subjetiva, estabelecendo um contrato de confiança com o destinatário, o que permite inferir que haja um alto grau de franqueza, pelos locutores (ABs), em relação ao discurso que produzem. Os destinatários-alvo dos relatos são, nesse caso, as professoras orientadoras, podendo figurar, para o $\mathrm{AB}$, a posição tradicional do professor avaliador, que valida a sua permanência no programa, como "bolsista" (no sentido financeiro mesmo, ou seja, do aluno que necessita dessa bolsa para continuar no curso). Além disso, os ABs também são alunos dessas professoras no Curso de Pedagogia, o que pode configurar a produção do relato como mais uma forma de avaliação de seu desempenho como "aluno da pedagogia" (futuro professor).

Outras posições que esses alunos podem assumir, na produção dos relatos, referem-se às funções que, comumente, são assumidas pelo $\mathrm{AB}$ : pesquisador/observador, avaliador, segundo professor/professor auxiliar. Assumindo essas posições, 
é possível hipotetizar que esse aluno vai procurar passar uma boa imagem de sua atuação, em uma produção escrita de "pesquisador" para "orientador" ou até mesmo de "professor" para "professor”. Nesse sentido, é possível que uma posição que esse aluno (o $\mathrm{AB}$ ) tente apagar é a de "estagiário", no sentido mais convencional do termo e da função. O que significa que o $A B$ vai querer demonstrar que está desempenhando bem a sua função.

Levantadas algumas hipóteses sobre a situação de produção dos relatos, apresentamos, a seguir, as análises de texto, conforme procedimentos explicitados.

\section{PLANO GLOBAL DOS RELATOS REFLEXIVOS}

Para explicitar o plano global dos relatos reflexivos, procuramos identificar como os temas são desenvolvidos nos textos, observando quais são mais focalizados ou apagados; como também as sequências textuais predominantes (narrativas, descritivas, argumentativas, expositivas etc.), entre outros aspectos que se referem à construção composicional dos relatos.

Com base nessas observações, verificamos que os relatos fazem referências às atividades de rotina das aulas realizadas pelo professor-regente: atividades de leitura feita pelo professor, atividades de sondagem, ditados, produção escrita compartilhada em que o professor é o escriba, entre outras características da alfabetização. Organizando-se, geralmente, com referência a essas atividades de rotina, os relatos se iniciam, quase sempre, tratando da primeira atividade da rotina do professor-regente, ou então com uma ancoragem temporal, sobre o período de observação a que se refere o relato, como no exemplo a seguir:

Exemplo 1: (R3AP)

A professora inicia a aula todos os dias pela leitura, mas sem significado algum [...]

A narrativa é a sequência textual predominante nos relatos, revelando não só as experiências particulares de cada $A B$, 
mas também sua maneira de estruturar os componentes do relato. Contudo, para dar-lhe sentido, os autores dos relatos mobilizam seus sentimentos, impressões e conhecimentos, constituindo seus textos com a presença de diferentes sequências textuais (narração, argumentação, exposição, entre outros) e diversas vozes, tornando os relatos heterogêneos, complexos, uma verdadeira mistura de elementos, o que é característico do gênero, como se pode ver no exemplo a seguir:

Exemplo 2: (R1MA)

A professora foi ensinando aos poucos, todos os dias ensinava uma letrinha diferente, passava na lousa com uma letra grande e pedia para as crianças observarem os movimentos que ela fazia para desenhar aquela letra.

A professora acha que é muito cedo para ensinar a letra de mão, pois como ainda tem crianças que não são alfabéticas, vai acabar confundindo mais ainda a cabeça delas. Mas como as crianças e as próprias mães estavam insistindo ela ensinou. Agora tudo que é passado na lousa é escrito com a letra de mão, e as crianças são obrigadas a se virar.

Conclusão, uma boa parte da sala está acompanhando e fazendo direitinho, mas as crianças que não conseguem estão cada vez mais perdidas, o caderno está ficando um relaxo e as lições estão ficando incompletas, pois não conseguem acompanhar o ritmo das outras crianças.

Como se pode observar, no primeiro parágrafo, a autora do relato apresenta uma sequência narrativa de fatos, utilizando o pretérito imperfeito, distanciando-se do seu discurso, não se comprometendo, portanto, com o que é relatado. Já no segundo parágrafo, ao comentar a justificativa da professora ("A professora acha que é muito cedo para ensinar a letra de mão... mas, como as crianças e as próprias mães estavam insistindo, ela ensinou”.), há maior engajamento da autora do relato com aquilo que enuncia, isto é, existe uma atenção maior do locutor ao que é enunciado, criando um comprometimento com os interlocutores que estão diretamente envolvidos no discurso. No último parágrafo, assumindo uma posição mais pessoal 
e subjetiva, a autora do relato faz apreciações/avaliações ao comentar as consequências do agir da professora no agir dos alunos, isto é, no processo de aprendizagem desses alunos.

Pode-se verificar, também, na maioria dos relatos, no início ou no final do texto, uma avaliação global sobre o que foi observado/vivenciado ao longo de um mês pelo $A B$, com apreciação positiva ou negativa do agir da professora, como no exemplo abaixo:

Exemplo 3: (R3AP3) - Trecho que aparece no final do relato

Minha professora [a professora-regente], uma senhora, realmente é apaixonada pelo que faz. Intercala seus métodos, porém, o faz de forma consciente, pois aplica atividades diferentes diante das dificuldades que os alunos apresentam, sendo, assim, acaba por recorrer ao método tradicional devido a dificuldade do aluno.

Por outro lado, compreende que são crianças e que estão passando pelo processo de adaptação, principalmente por ser uma escola de período integral. Tendo em vista isso, procura sempre manter um ambiente alegre e "infantil", decora a sala de acordo com o que está trabalhando, faz brincadeiras, e dá muito carinho e atenção, demonstrando isso para os alunos mesmo quando brava ou chateada. Leva em consideração os conhecimentos de seus alunos, seus avanços e conquistas. Concluindo, ela torna o ambiente de aprendizagem divertido, prazeroso e "produtivo".

Outro aspecto típico dos relatos são as conviç̧ões ou dúvidas dos $A B s$ que podem aparecer em diferentes espaços do texto: na introdução, no desenvolvimento ou na conclusão, fazem intercalações, perguntas, reticências que mostram suas certezas ou incertezas sobre o ensino e a aprendizagem na alfabetização. O exemplo a seguir evidencia essa característica.

Exemplo 4: (R1DA)

A professora pediu para que eu ficasse com cinco alunas em um canto da sala para trabalhar com o alfabeto, porque elas ainda não conheciam todas as letras. Posso dizer que me desesperei e parei para pensar se isso era realmente o que eu queria. 
Outro conteúdo temático recorrente nos relatos é a manifestação dos ABs quanto ao ganho de experiência e à importância de sua participação no programa, como evidencia o relato a seguir:

Exemplo 5: (R1MA)

Participar desse projeto está sendo maravilhoso, pois estou podendo ver de perto o que acontece realmente em uma sala de aula, tanto as coisas boas como as coisas ruins. Além do prazer vivenciado a cada dia, podendo notar os progressos de cada aluno e o carinho em que demonstram ter com você, percebo que de certa forma estou fazendo a diferença para aquelas crianças.

Um fato que chama a atenção, com relação ao conteúdo temático dos relatos produzidos no primeiro ano de participação no programa (Período 1) e dos produzidos no terceiro ano (Período 3), é que, no início, os $\mathrm{ABs}$ fazem muitas referências às relações afetivas, tanto do professor-regente com as crianças e com o próprio $\mathrm{AB}$, quanto deste com as crianças, tema pouco frequente nos textos produzidos no Período 3. Além disso, no Período 1, o agir do professor é o foco principal das reflexões; já no Período 3 amplia-se a referência nos relatos ao agir dos alunos.

É importante ressaltar também que, embora os $\mathrm{ABs}$ tenham o compromisso de entregar os seus textos para as professoras orientadoras, quase não se observa nos relatos referência a esses interlocutores. Certamente, isso ocorre porque não há uma preocupação dessa ordem por parte dos ABs, o que, aliás, é uma característica, de modo mais amplo, do gênero relato reflexivo.

Em síntese, o conteúdo temático dos relatos reflexivos selecionados para análise e, consequentemente, o seu plano global, se relaciona às diferentes fases de uma aula de alfabetização, podendo ser representado, de modo geral, pela rotina das aulas do professor-regente, no que se refere à leitura e escrita, com descrição, comentários e avaliação 
pelo $\mathrm{AB}$ das atividades que ele considera relevante tematizar em seu relato, seja para uma apreciação positiva e/ou negativa.

A seguir, tratamos da identificação dos actantes (protagonistas do agir) constantes dos relatos reflexivos selecionados para análise.

\section{OS ACTANTES POSTOS EM CENA NOS/PELOS RELATOS REFLEXIVOS}

A partir da análise do plano global, procuramos identificar os actantes postos em cena nos/pelos textos produzidos nos Períodos 1 e 3, para observar melhor se/como os ABs vão (re)construindo seu foco de observação das situações de ensino e aprendizagem vivenciadas ao longo da participação no Programa Bolsa Alfabetização. Nessa identificação, por meio dos marcadores de pessoa, ainda buscamos detectar o estatuto individual ou coletivo atribuído ao agir do professor-regente (PR) e do $\mathrm{AB}$, isto é, quando esses são postos em situação individual ou conjunta (PR e $A B)$, ou PR e outro(s) professor(es). Na tabela 1 é apresentado o número de ocorrências por actante nos relatos produzidos nos Períodos 1 e 3. 
TABELA 1 - Número de ocorrências por tipo de actante, identificados em relatos reflexivos nos Períodos 1 e 3

\begin{tabular}{|c|c|c|c|}
\hline \multirow{2}{*}{$\begin{array}{l}\text { ACTANTES IDENTIFICADOS NOS } \\
\text { RELATOS REFLEXIVOS }\end{array}$} & \multicolumn{2}{|c|}{ NÚMERO DE OCORRÊNCIAS } & \multirow{2}{*}{ TOTAL } \\
\hline & Período 1 & Período 3 & \\
\hline Professor-regente & 385 & 306 & 691 \\
\hline Aluno-pesquisador & 92 & 164 & 256 \\
\hline Aluno(s)/criança(s) & 130 & 208 & 338 \\
\hline Professor-regente e aluno-pesquisador & 5 & 18 & 23 \\
\hline Professor-regente e outro(s) professor(es) & 1 & 5 & 6 \\
\hline Pais dos alunos & 3 & 8 & 11 \\
\hline Professoras orientadoras da USCS & 0 & 2 & 2 \\
\hline Diretor/coordenador da escola & 2 & 4 & 6 \\
\hline Diretoria de ensino/SEE/FDE & 1 & 2 & 3 \\
\hline Professores da pedagogia da USCS & 1 & 2 & 3 \\
\hline
\end{tabular}

Fonte: Elaboração da autora.

Como se pode verificar na Tabela 1 , no primeiro e terceiro ano de participação no programa, o professor-regente é o actante mais referenciado nos relatos (385 e 306 ocorrências respectivamente); embora no terceiro ano haja uma diminuição das referências ao agir do professor-regente e um aumento das referências às crianças (130 e 208 ocorrências respectivamente). Com isso, pode-se justificar, a nosso ver, que a maior ocorrência do actante "professor" nos relatos deve-se à concepção de ensino dos ABs estar centrada em "como se ensina” em detrimento de "como se aprende". Por isso, inicialmente, o AB considera o agir dos alunos como secundário. Observa-se, contudo, nos relatos produzidos no terceiro ano, uma elevação da referência ao actante "aluno" (208). O que pode indicar uma (re) elaboração de concepções de ensino, com maior preocupação do $\mathrm{AB}$ de observar como as crianças aprendem. Vale lembrar que esse é um aspecto bastante debatido na formação dos ABs na USCS, a discussão sobre a análise dos registros de situações de sala de aula que vivenciam. Insistimos sempre que os ABs observem e reflitam não apenas sobre como o professor ensina, mas também e, principalmente, como os alunos constroem conhecimentos sobre a língua no processo de alfabetização. 
Outro dado relevante nesse levantamento refere-se à ocorrência do actante $A B$, que aumenta de 92 (no primeiro ano) para 164 (no terceiro ano), o que pode ser justificado pelo próprio processo de construção pelo licenciando de seu espaço na sala de aula, de sua função como AB. Inicialmente, ele atua mais como observador e, aos poucos, assume algumas tarefas em relação os alunos, ressaltando-se que essa é a orientação do próprio programa. Obviamente, esse processo também depende da boa interação do professor-regente e do $A B$. Pode-se indicar que os professores-regentes, à medida que vão compreendendo melhor o papel do $A B$, passam a dar mais espaço para a atuação dele na sala de aula.

Os dados indicam, no entanto, que o actante $A B$ aparece, nos dois períodos, muito mais com o estatuto de um agir individual do que coletivo, em parceria com o professor-regente. Isso pode indicar que o $\mathrm{AB}$ atua na sala de aula separadamente do professor, com mais frequência do que em parceria.

Conforme orientações do programa, cabe ao $\mathrm{AB}$ assumir, gradativamente, de comum acordo com o professor-regente e com o professor-coordenador, algumas funções para auxiliar no planejamento e execução das atividades de sala de aula, sendo que crianças com maior grau de dificuldade não podem ficar sob a responsabilidade do $A B$, uma vez que esse ainda não possui embasamento teórico-metodológico e amadurecimento profissional. Contudo, os relatos reflexivos evidenciam que os $\mathrm{ABs}$ têm atuado individualmente (sozinhos), sobretudo com os alunos que apresentam maiores dificuldades no processo de alfabetização.

Quanto aos outros actantes que aparecem nos relatos, há algumas referências ao agir coletivo do professor-regente com outros professores da escola, principalmente em situações de atividades de projetos culturais da escola. Já quando aparece a direção e/ou coordenação da escola, assim como Diretoria de Ensino, FDE/SEE, a referência é, geralmente, em situações de reunião na escola.

Quanto aos professores orientadores do Programa, as poucas vezes em que aparecem nos relatos, as referências são com relação ajuda/orientação desses professores para 
a atuação do $\mathrm{AB}$ nas classes de alfabetização. No caso dos professores da Pedagogia, estes são referenciados quando o AB faz uma comparação, positiva ou negativa, com o que diz(em) o(s) professor(es) e o que o $\mathrm{AB}$ vivencia na escola.

A seguir, trataremos dos modos de agir do professor-regente (re)configurados pelo $\mathrm{AB}$ nos/pelos relatos reflexivos.

\section{MODOS DO AGIR DO PROFESSOR-REGENTE (RE)CONFIGURADOS NOS/PELOS RELATOS REFLEXIVOS}

Para a análise de como os ABs (re)configuram, em seus relatos reflexivos, os modos de agir do professor-regente, fizemos, primeiramente, um recorte, selecionando os relatos produzidos no Período 3, identificamos e quantificamos os modos de agir do professor-regente (re)configurados pelos ABs nesses textos.

Os resultados desse primeiro levantamento ajudaram na seleção dos dados para a análise dos modos de agir detectados mais recorrentes nos relatos reflexivos. Assim, investigamos com cuidado os textos selecionados para análise, buscando identificar nas referências ao agir do professor-regente, marcas linguístico-discursivas (modalizações, adjetivos, verbos, advérbios etc.) que evidenciem como os ABs interpretam e avaliam um determinado modo de agir do professor-regente.

A seguir, a Tabela 2 que evidencia os modos de agir do professor, acompanhado de um exemplo, para melhor compreensão de cada modo, e o número de ocorrências. 
TABELA 2 - Número de ocorrências por modo de agir do professor-regente (re)configurado nos relatos reflexivos do Período 3

\begin{tabular}{|c|c|c|}
\hline MODOS DE AGIR & $\begin{array}{l}\text { NÚMERO DE } \\
\text { OCORREENCIAS }\end{array}$ & UM EXEMPLO \\
\hline Linguageiro & 69 & $\begin{array}{l}\text { Ela [a professora] explicou para eles [alunos] por que a Marcela } \\
\text { (personagem da história) é especial; porque ela é cega }\end{array}$ \\
\hline $\begin{array}{l}\text { Com instrumentos } \\
\text { (materiais e/ou } \\
\text { simbólicos) }\end{array}$ & 146 & $\begin{array}{l}\text { Primeiro ela [a professora] mostra o desenho da letra na tabela, } \\
\text { por exemplo, a letra "a", logo após mostra para a classe como se } \\
\text { faz o desenho da letra no modo cursivo }\end{array}$ \\
\hline Cognitivo/capacidade & 42 & $\begin{array}{l}\text { A professora não dava tempo para os alunos pensarem e fazerem } \\
\text { com calma a atividade }\end{array}$ \\
\hline Prescritivo & 21 & $\begin{array}{l}\text { A professora segue uma rotina diária determinada pela direção } \\
\text { da escola }\end{array}$ \\
\hline Afetivo & 23 & $\begin{array}{l}\text { Percebo que a professora gosta dos alunos, mas ao mesmo } \\
\text { tempo está descontente com a escola e os métodos }\end{array}$ \\
\hline Corporal/físico & 05 & $\begin{array}{l}\text { Outro dia vi a professora pegar no braço de um aluno com força, } \\
\text { provocando o choro }\end{array}$ \\
\hline
\end{tabular}

Fonte: Elaboração da autora.

Como pode ser observado, o maior número de ocorrências dos modos de agir do professor tematizados nos relatos refere-se ao "agir com instrumentos" (146 ocorrências). Por isso, é importante nos determos na análise dos segmentos que tematizam esse modo de agir do professor-regente.

As (re)configurações dos modos de agir com instrumento envolvem a referência ao uso pelo professor-regente de instrumentos materiais e/ou simbólicos característicos do trabalho do alfabetizador, tais como a escrita, as letras, cartazes, alfabeto móvel, imagens, desenhos, objetos e materiais didáticos, livros infantis, materiais do Ler e Escrever, móveis da classe, entre os diversos artefatos que fazem parte desse coletivo de trabalho. Em suma, esse modo de agir mostra o caráter instrumental do trabalho do professor, como no exemplo na próxima página: 
Exemplo 6 (R3JA)

A professora organiza a sala de aula possibilitando aos alunos as consultas espontâneas, há o alfabeto com ilustrações, numerais e um cartaz com o nome das crianças, cantos onde as crianças dispõem de livros de histórias para levar pra casa e, nesse mesmo local, são guardados os livros didáticos que as crianças utilizam em sala. Assim, o espaço da própria sala de aula oferece incentivos à leitura. [...] Com as observações acima citadas verifica-se o esforço da professora para que os alunos tornem-se excelentes escritores e leitores capazes de interagirem adequadamente nas funções sociais das duas práticas (leitura e escrita).

Esse destaque para o agir instrumental do trabalho do professor-regente sinaliza também que o $A B$ atenta para as formas de apropriação, pela professora, dos instrumentos mediadores do trabalho prescrito pelas orientações/propostas curriculares de alfabetização - divulgadas pela SEE/FDE, Programa Ler e Escrever, Diretoria de Ensino, Coordenação da escola etc. -, para atender ao objetivo principal que é ensinar as crianças a ler e a escrever. São esses instrumentos: livros de histórias, livros didáticos, alfabeto, cartazes, textos de diversos gêneros, figuras, parlendas, cruzadinhas, listas, músicas etc.

Interessante observar ainda que os ABs, ao focalizarem os modos de agir com instrumento, fazem mais comentários apreciativos - positivos e/ou negativos - a respeito dos modos de agir do professor-regente. Como se pode ver no Exemplo 6, há uma descrição do agir com instrumentos da professora, acompanhada de uma interpretação e avaliação pelo $A B$ desse agir. Além disso, constatamos que esses comentários apreciativos são mais recorrentes ainda quando os ABs se referem à atividade de leitura feita pelo professor. $\mathrm{O}$ interesse por essa atividade também é evidenciado quando, dentre os temas que o Bolsa Alfabetização propõe para a realização da investigação didática, "leitura feita pelo professor" é o mais abordado pelos ABs da USCS em seus trabalhos. Uma explicação para isso pode ser o fato de essa leitura, assim como os diferentes procedimentos para realizá-la, é uma prática 
bastante valorizada, utilizada e discutida na Educação Infantil, em que a maioria desses ABs já atua, inclusive realizando a leitura para as crianças.

No quadro a seguir, interpretações do $A B$ do agir instrumental do professor-regente na atividade de leitura feita pelo professor, em dois trechos: um com apreciação positiva e outro com negativa.

QUADRO 1 - Interpretações/avaliações dos modos de agir do professor-regente em atividades de leitura feita pelo professor

\begin{tabular}{|c|c|c|c|}
\hline TRECHO DO RELATO & $\begin{array}{c}\text { ELEMENTOS LINGUÍSTICO- } \\
\text { DISCURSIVOS DA } \\
\text { INTERPRETAÇÃO/ } \\
\text { AVALIAÇÃO DO AB }\end{array}$ & $\begin{array}{l}\text { NATUREZA } \\
\text { DA } \\
\text { APRECIAÇÃO }\end{array}$ & $\begin{array}{l}\text { CRITÉRIOS/ } \\
\text { JUSTIFICATIVAS }\end{array}$ \\
\hline $\begin{array}{l}\text { A professora faz a leitura do gênero bilhete, } \\
\text { com um assunto que era algo de grande } \\
\text { interesse das crianças, o sumiço da vassoura } \\
\text { da sala, conhecida por eles como uma bruxa, } \\
\text { o que criou muitas expectativas nos alunos, } \\
\text { que ao final quiseram comentar. Podemos ver } \\
\text { através desse relato que a professora além } \\
\text { de trazer uma leitura de bilhete escrito por } \\
\text { alguém conhecido, usou de um assunto que } \\
\text { também trazia muito entusiasmo aos alunos, } \\
\text { por ser um fato que realmente aconteceu } \\
\text { (sumiço da vassoura), o que contribui } \\
\text { chamando a atenção dos alunos que ficaram } \\
\text { prestativos na hora da leitura, e com certeza } \\
\text { conseguiram prestar mais atenção nas } \\
\text { características desse gênero. (R3AL) }\end{array}$ & $\begin{array}{l}\text { - grande interesse; } \\
\text { - entusiasmo; } \\
\text { - criou muitas expectativas; } \\
\text { - além de [...] usou também; } \\
\text { - alguém conhecido; } \\
\text { - muito entusiasmo; } \\
\text { - fato que realmente aconteceu; } \\
\text { - contribui; } \\
\text { - chamando a atenção; } \\
\text { - prestativos na hora da leitura; } \\
\text { - prestar atenção nas } \\
\text { características do gênero. }\end{array}$ & Positiva & $\begin{array}{l}\text { - a escolha do texto a } \\
\text { ser lido pelo professor; } \\
\text { - texto com } \\
\text { proximidade da } \\
\text { realidade dos alunos; } \\
\text { - efeitos da leitura nos } \\
\text { alunos; } \\
\text { - ensino/aprendizagem } \\
\text { das características } \\
\text { do gênero do texto a } \\
\text { ser lido. }\end{array}$ \\
\hline $\begin{array}{l}\text { A professora começou a aula fazendo a } \\
\text { leitura da "Cinderela", no mesmo ambiente } \\
\text { rotineiro, chamando atenção dos alunos a } \\
\text { todo o momento. Parou no meio da história } \\
\text { pretendendo continuar no dia seguinte. } \\
\text { Depois retomou os pontos principais com } \\
\text { as crianças, solicitando para que as mesmas } \\
\text { contassem. } \\
\text { Após a leitura, a professora e as duplas } \\
\text { trabalharam normalmente. A professora } \\
\text { escolheu a história a olho, não sabia e nem } \\
\text { lembrava as histórias que já haviam sido lidas } \\
\text { e as crianças foram ajudando ela recordar as } \\
\text { histórias repetidas. } \\
\text { Não houve nenhuma atividade específica } \\
\text { após o término da leitura, e no dia seguinte, } \\
\text { a professora não retomou a mesma. (R3DA) }\end{array}$ & $\begin{array}{l}\text { - mesmo ambiente rotineiro; } \\
\text { - chamando atenção a todo } \\
\text { momento; } \\
\text { - escolheu história a olho; } \\
\text { - não sabia e nem se lembrava } \\
\text { histórias lidas; } \\
\text { - não houve atividade após a } \\
\text { leitura; } \\
\text { - a professora não retomou a } \\
\text { história. }\end{array}$ & Negativa & $\begin{array}{l}\text { - escolha do texto } \\
\text { e planejamento da } \\
\text { leitura; } \\
\text { - ambiente da leitura; } \\
\text { - textos conhecidos } \\
\text { pelo professor; } \\
\text { - intervenções antes, } \\
\text { durante e depois da } \\
\text { leitura; } \\
\text { - respeito aos contratos } \\
\text { estabelecidos } \\
\text { professor/alunos. }\end{array}$ \\
\hline
\end{tabular}

Fonte: Elaboração da autora.

Os dados do quadro sinalizam que há uma compreensão, por parte do $\mathrm{AB}$, de que a leitura envolve emoção, interesse, o que pode ser despertado pela qualidade do texto a ser lido, pela familiaridade com o tema/assunto do texto, pelo contexto do momento da leitura. Essas são, pois, concepções mobilizadas pelos ABs, sob as formas pelas quais (re)configuram os modos de agir 
do professor-regente e interpretam/avaliam esse agir, nos momentos de ação de linguagem, ou seja, nos seus relatos reflexivos.

Além disso, os ABs, ao (re)configurarem modos de agir do professor-regente com o instrumento "texto escrito" (bilhete sobre o sumiço da vassoura ou conto da Cinderela), expressam aspectos que consideram mais adequados quanto à utilização dos recursos materiais/simbólicos disponíveis no coletivo de trabalho de alfabetização, mais especificamente na atividade de leitura feita pelo professor). Aspectos esses que, na visão dos ABs, possibilitariam a criação de condições para que as crianças "se interessem", "se entusiasmem" pela história, para que possam compreendê-la, apreciá-la, apreendê-la, dando oportunidade de desenvolvimento cognitivo aos alunos. Isso pode ser percebido pelas expressões de interpretação positiva sobre o agir do professor (criou muitas expectativas; além de [...] usou também; contribui) e negativa (escolheu a história a esmo; não sabia nem se lembrava da história etc.), bem como os critérios que estão implícitos nessa interpretação. $\mathrm{O}$ que significa dizer que os $\mathrm{ABs}$, ao focalizar mais especificamente a dimensão instrumental do trabalho docente, demonstram reconhecer a importância do planejamento, da seleção e do conhecimento do texto a ser lido, bem como da qualidade das intervenções do professor antes, durante e depois da leitura, na atividade de leitura feita pelo professor. Enfim, ações consideradas essenciais pelos ABs para a adequada mobilização dos instrumentos utilizados pelo professor.

Esse reconhecimento remete a uma relação que o $\mathrm{AB}$ faz com as prescrições do trabalho do alfabetizador, conforme trecho do material do Ler e Escrever que faz referência a esses aspectos apontados pelos ABs nos relatos:

A prática de leitura realizada pelo professor deve ser constante em sala de aula. Para garantir que a história seja significativa, é importante que o narrador a aprecie (passando sua emoção para ela), que planeje (escolhendo o que irá ler de acordo com o gosto, a idade e as condições socioeconômicas dos alunos, passando segurança e naturalidade a quem ouvir a história) e estude a história (entendendo e captando a mensagem da leitura), 
aprendendo então a melhor forma de contá-la. [...] Ao planejar o momento da leitura, selecione para comentar as passagens que lembram outras histórias/personagens, aquelas que despertam sentimentos fortes (medo, alegria, tristeza) ou então aquelas que lembram acontecimentos recentes, da sua vida ou do dia-a-dia dos alunos. (SÃO PAULO, 2008, v. 1, p. 61)

Essa relação com o trabalho prescrito, no que se refere à atividade de leitura feita pelo professor, pode ser motivada também pelo fato de o destinatário/leitor do relato reflexivo ser o professor orientador da IES, a quem o $\mathrm{AB}$ dirige seus comentários, suas avaliações sobre o trabalho do professor-regente. Assim, o AB pode querer passar uma boa imagem sobre ele mesmo, assumindo a posição de um aluno de pedagogia (futuro professor) que conhece as concepções e orientações atuais de ensino e aprendizagem da língua.

Além disso, caberia uma análise mais detalhada das prescrições do Programa Ler e Escrever para essa afirmação, mas essas prescrições também podem privilegiar esse caráter instrumental do agir docente, o que acaba por reforçar as concepções do trabalho docente (re)construídas pelo $\mathrm{AB}$.

De qualquer maneira, o fato é que, a partir dessas interpretações/avaliações do agir da professora-regente, assim como desse entrecruzamento de diferentes posições e vozes que emergem em seus relatos reflexivos, esse sujeito $(\mathrm{AB})$ (re)constrói e (re)elabora suas crenças e concepções.

Além dessas constatações, certamente é possível identificar outros elementos, relativos à prática de leitura feita pelo professor na alfabetização, que os ABs demonstram (re) conhecer, se examinarmos cada um dos segmentos textuais que têm o professor-regente como actante em situações de leitura para os alunos. Assim, também, se analisarmos outros modos de agir, tanto do professor e do próprio $A B$ quanto das crianças e outros actantes, (re)configurados nos relatos pelos licenciandos. Há, portanto, muitas outras possibilidades de análises dessas produções textuais à luz do ISD. 
Em suma, as análises que realizamos permitiram a explicitação e a compreensão de alguns aspectos sobre como alunos de pedagogia, participantes do Programa Bolsa Alfabetização constroem o seu lugar e os seus papéis como $\mathrm{AB}$ e como vão se constituindo professores, apropriando-se dos modos de agir docente, à medida que observam e participam do processo de ensino e aprendizagem na alfabetização, com oportunidades de refletir sobre esse processo, sobretudo, na/pela escrita.

\section{CONCLUSÃO}

Os resultados principais da pesquisa que realizamos apresentados neste artigo forneceram algumas pistas que levam a uma melhor compreensão do processo de formação docente dos licenciandos, inseridos em um contexto diferenciado de formação inicial propiciado pelo Programa Bolsa Alfabetização.

Os resultados da análise evidenciam alguns aspectos do processo de formação de alunos de pedagogia participantes do Programa Bolsa Alfabetização que permitem, por sua vez, questionamentos que envolvem as ações de formação docente, empreendidas não apenas pelo programa como também pelo contexto geral de formação de professores, principalmente, na Pedagogia, a saber:

- a inserção do $A B$ no cotidiano da sala de aula propicia a familiarização desse futuro professor com o processo de ensino e aprendizagem na alfabetização nas diferentes situações didáticas que emergem nesse contexto;

- essa familiarização está sendo orientada por uma abordagem de reflexão sobre a prática docente na perspectiva da investigação didática proposta pelo programa;

- essa reflexão tem envolvido apenas o AB. Certamente a formação do AB é o foco do programa, mas o diálogo dos atores envolvidos nesse contexto formativo não ocorre, por exemplo, entre a escola, o professor-regente, o aluno-pesquisador e o profes- 
sor orientador da universidade. Como demonstraram as análises dos relatos reflexivos, tem ocorrido muito pouco diálogo entre professor-regente e $A B$;

- no que se refere à reflexão do $\mathrm{AB}$ e, consequentemente, à sua formação, há o predomínio da concepção do trabalho docente como uma atividade predominantemente instrumental, negligenciando outras dimensões desse trabalho, já bastante debatidas no campo da investigação da didática de língua materna, tais como: contrato didático, transposição didática, interação em sala de aula, saberes e práticas de referência, planificação didática, sequência didática, regulação das aprendizagens e avaliação. Dimensões essas consideradas essenciais, mas que estão praticamente ausentes desse processo de formação e, portanto, não aparecem nos relatos dos $\mathrm{ABs}$.

Como já foi apontado, o Programa Bolsa Alfabetização apresenta um avanço ao incluir a perspectiva da investigação didática na formação do $\mathrm{AB}$. Mas, certamente o projeto ganhará mais força estabelecendo o diálogo direto da escola com a universidade, incluindo também professor-regente na abordagem formativa da investigação didática.

Além disso, a perspectiva da investigação didática, não apenas no Programa Bolsa Alfabetização, mas no âmbito da formação docente na pedagogia, necessita ser ampliada na direção dos estudos desenvolvidos por pesquisadores do grupo de didática de línguas da Universidade de Genebra, como Schneuwly, Dolz, Gagnon e Decandio, nos quais Delia Lerner se inspira certamente.

Em linhas gerais, a didática das línguas estuda os fenômenos de ensino e aprendizagem das línguas (materna ou estrangeira) e as relações complexas entre os três polos do triângulo didático: o ensino, o aluno e a(s) língua(s) ensinada(s) (DOLZ; GAGNON; DECANDIO, 2009). Em outras palavras, os estudos da didática das línguas abordam a análise das práticas de sala de aula privilegiando as formas de adequação do ensino às capacidades dos alunos, às interações, às tarefas realizadas, aos objetos efetivamente ensinados na aula, às ferramentas/instrumentos de ensino. 
Com isso, busca-se objetivar e modelizar os fenômenos de ensino-aprendizagem de língua(s) com vistas a oferecer apoio para o professor e para a formação profissional.

Nesse sentido, uma formação de professores preocupada com as diversas dimensões e componentes do trabalho docente deve buscar a explicitação dessas noções na análise das práticas reais de sala de aula. Pois, como bem ressalta Lerner (2002), somente estudando os mecanismos e os fenômenos que ocorrem na escola e impedem a aprendizagem das crianças é que será possível pensar em questões relativas ao bom resultado do trabalho e do empenho dos educadores pela melhoria do ensino.

\section{REFERÊNCIAS}

BAKHTIN, Mikhail. Marxismo e filosofia da linguagem. São Paulo: Hucitec, 1981.

BARRICELLI. Ermelinda. A reconfiguração pelos professores da proposta curricular de educação infantil. 2007. Dissertação (Mestrado em Linguística Aplicada e Estudos da Linguagem) - Pontifícia Universidade Católica de São Paulo, São Paulo, 2007.

BRONCKART, Jean-Paul. Atividade de linguagem, textos e discursos: por um interacionismo sociodiscursivo. São Paulo: Educ, 1999.

Pourquoi e comment analyser l'agir verbal e non verbal en situation de travail? Les Cahiers de la section des Sciences de l'Éducation de la FAPSE, Genève, n. 103, p. 9-10, 2004.

Atividades de linguagem, discurso e desenvolvimento humano.

Campinas: Mercado de Letras, 2006.

O agir nos discursos: das concepções teóricas às concepções dos trabalhadores. Campinas: Mercado de Letras, 2008.

BRONCKART, Jean Paul; MACHADO, Anna Rachel. Procedimentos de análise de textos sobre o trabalho educacional. In: MACHADO, Anna Rachel (Org.). 0 ensino como trabalho: uma abordagem discursiva. Londrina: Eduel, 2004. p. 131-165.

BUENO, Luzia. A construção de representações sobre o trabalho docente: o papel do estágio. 2007. Tese (Doutorado em Linguística Aplicada e Estudos da Linguagem) - Pontifícia Universidade Católica de São Paulo, São Paulo, 2007. 
DOLZ, Joaquim; GAGNON, Roxane; DECÂNDIO, Fabrício Roberto.

Uma disciplina emergente: a didática das línguas. In: NASCIMENTO,

Elvira Lopes (Org.). Gêneros textuais: da didática das línguas aos objetos de ensino. São Carlos: Claraluz, 2009. p. 19-50.

FERREIRO, Emilia; TEBEROSKY, Ana. Psicogênese da língua escrita.

Porto Alegre: Artmed, 1985.

GATTI, Bernardete Angelina; NUNES, Marina Muniz Rosa (Org.). Formação de professores para o ensino fundamental: estudo de currículos das licenciaturas em pedagogia, língua portuguesa, matemática e ciências biológicas. São Paulo: Fundação Carlos Chagas, 2009. (Coleção Textos FCC, v. 29)

GATTI, Bernardete Angelina et al. Formação de professores para o ensino fundamental: instituições formadoras e seus currículos. São Paulo: Fundação Carlos Chagas; Fundação Victor Civita, 2008. (Relatório de pesquisa)

KLEIMAN, Angela B. Letramento e formação do professor: quais as práticas e exigências no local de trabalho? In: KLEIMAN, Angela B. (Org.). A formação do professor: perspectivas da linguística aplicada. Campinas: Mercado de Letras, 2001. p. 39-68.

LERNER, Delia. Ler e escrever na escola: o real, o possível e o necessário. Porto Alegre: Artmed, 2002.

MACHADO, Anna Rachel (Org.). O ensino como trabalho: uma abordagem discursiva. Londrina: Eduel, 2004.

Por uma concepção ampliada do trabalho do professor. In: GUIMARÃES, Ana. Maria M.; MACHADO, Anna Rachel; COUTINHO, Antonia (Org). 0 interacionismo sociodiscursivo: questões epistemológicas e metodológicas. Campinas: Mercado de Letras, 2008. p. 77-97.

- Trabalho prescrito, planificado e realizado na formação de professores: primeiro olhar. In: Machado, Anna Rachel et al. Linguagem e educação: o trabalho do professor em uma nova perspectiva. Campinas: Mercado de Letras, 2009. Cap. 3, p. 79-116.

Colaboração e crítica: possíveis ações do linguista na atividade educacional. Veredas, Juiz de Fora, n. 2, p.22-40, 2007. Disponível em: <http://www.uff.br/revistaveredas/files/2009/12/artigo021.pdf >. Acesso em: 2 jul. 2013.

MAZZILLO, Tania Maria da Frota Mattos. 0 trabalho do professor em língua estrangeira representado e avaliado em diários de aprendizagem. 2006. Tese (Doutorado em Linguística Aplicada e Estudos da Linguagem) Pontifícia Universidade Católica, São Paulo, 2006. Disponível em: <http:// www.sapientia.pucsp.br/tde_arquivos/19/TDE-2007-07-25T05:33:01Z-3874/ Publico/Tania\%20Mazzillo.pdf>. Acesso em: 2 jul. 2013.

MORIN, Edgar. Epistemologia da complexidade. In: SCHNITMAN, Dora. Fried. (Org.). Novos paradigmas, cultura e subjetividade. Porto Alegre: Artes Médicas, 1996. p. 274-279. 
MUNIZ-OLIVEIRA, Sirlene. O trabalho representado do professor de pós-graduação de uma universidade pública. 2011. Tese (Doutorado em Linguística Aplicada e Estudos da Linguagem) - Pontifícia Universidade Católica de São Paulo, São Paulo, 2011.

SÃO PAULO (Estado). Secretaria da Educação. Ler e escrever: guia de planejamento e orientações didáticas; professor alfabetizador $-1^{\mathrm{a}}$ série, 1 . São Paulo: FDE, 2008. Disponível em: <http://www.profdomingos.com.br/guia planejamento_orient_did_primeira_volume_um.pdf>. Acesso em: 2 jul. 2013.

SIGNORINI, Inês. O gênero "relato reflexivo" produzido por professores da escola pública em formação continuada. In: SIGNORINI, Inês. (Org.). Gêneros catalisadores, letramento e formação do professor. São Paulo: Parábola, 2006. p. 53-70.

WEISZ, Telma Formação, avaliação e políticas públicas. Lectura y vida: Revista Latino Americana de Lectura, Buenos Aires, v. 31, n. 4, p. 19-26, Dic. 2010.

\author{
ANA SÍLVIA MOÇO APARÍCIO \\ Professora Titular da Escola de Educação da Universidade \\ Municipal de São Caetano do Sul (USCS) \\ anaparicio@uol.com.br
}

